\title{
Ground Fissure Monitoring Based on 3D Terrestrial Laser Scanning Techniques
}

\author{
Lichun SUI ${ }^{1, a}$, Haixiong $\mathrm{ZHU}^{2, \mathrm{~b}}$, Chengxi Fang ${ }^{3, \mathrm{c}}$, Shuo $\mathrm{ZHAl}^{4, \mathrm{~d}}$ \\ College of Geology Engineering and Geomatics, ChangAn University, No.126 Yanta Road, Xi'an \\ 710054, China
}

National Administration of Surveying, Mapping and Geoinformation engineering research center of Geographic National Conditions Monitoring, Xi'an 710054, China

aemail: 524138055@qq.com, bemail: 951755015@qq.com

Keywords: subsidence; ground fissure monitoring; TLS

\begin{abstract}
Groundwater overdraft in Xi'an City is the main cause of the subsidence since 1959. In recent years, ground fissure has been one of the most serious geological hazards in Xi' an, China. This paper aims to research the application of high-precision 3D terrestrial laser scanning techniques (TLS) in land subsidence and ground fissure monitoring. The paper use TLS scanning to monitor a typical ground fissure in the southern suburb of Xi'an. Large-scale subsidence is obtained by processing and comprehensive analysis these fissure data, on the other hand, the paper investigate the characteristics of spatio-temporal evolution between the land subsidence and ground fissure. Finally, compared with Global Positioning System (GPS) measurement in the same period, TLS scanning result in tested area is reliable. The research shows that there is obvious spatio-temporal correlation between land subsidence and ground fissure distribution.
\end{abstract}

\section{Introduction}

In recent years, ground fissure has become one of the most serious geological hazard in the city of Xi' an, China. There are several techniques to monitor land subsidence. These include total station, vertical extensometers[1], leveling, GPS surveys[2], and spaceborne radar interferometry[3,4,5]. Leveling is a traditional subsidence monitoring technique, which is characterized by high accuracy, reliability, simple operation and equipments cheap[6]. GPS technique has advantages in high accuracy and simultaneous 3D positioning[7]. Differential Interferometric Synthetic Aperture Radar (D-InSAR) is an extensional application of interometry SAR (InSAR) technology, mainly used for DEM revision and refining, crust deformation monitoring, land subsidence monitoring and landslide monitoring[8,9].

This research has monitored land subsidence and ground fissures above area via high precision ground 3D terrestrial laser scanning (TLS) technique. The data was collected from a land subsidence and ground fissure areas. Comparison TLS and leveling data at the same period, we get deformation information and the fissure distribution.

\section{Methodology}

The land subsidence and ground fissure monitoring need a long-term time and repeated observations. In order to achieve monitoring, firstly, we set some ground control points, which were monitored by 
GPS when the laser carry out scanning and every monitored data transform to the coordinate system according to the ground control point. After the prepocessing, all the subsequent point clouds are registered into the coordinate system of the first scan. Then, we use the commercial software, such as Terrasolid software to filter no-ground targets information. Procedure is generally used combination of automation and manual interactive. Finally the point cloud data is carried out interpolation to generate DSM. As Ground fissures border steep and curvature features be concerned, keep features interpolation was used,

$$
\bar{f}(x, y)=\frac{\sum_{u=-n}^{n} \sum_{v=-n}^{n} f(x+u, y+v) \cdot g(x+u, y+v)}{\sum_{u=-n}^{n} \sum_{v=-n}^{n} g(x+u, y+v)}
$$

The weight equation is

$$
g(x, y)=g^{*}(d(x, y))=e^{-\frac{(d(x, y))^{2}}{2 \sigma^{2}}} .
$$

$d(x, y)$ i.e. the distance from interpolation point to known points.

Two or more period observed data comparison with differential DSM. The deformation of a land object consists in the change of the shape of its surface, due to sliding and subsidence of land objects along discontinuities. Thus the deformation analysis of a subsidence and fissure area surface surveyed at two or more epochs must comprehend two main stages. The first one is the change detection, which is focused to find an object that has subsidence and movement between two observation epochs. This is represented by the deformation analysis aimed to locate the areas that were affected by shape deformations. The first step before proceeding with both items is to compute a new matrix $\triangle \mathrm{DSM}$ resulting from the difference of the two DSMs concerning the same region:

$$
\Delta D S M=D S M^{t}-D S M^{t+1}
$$

The area-based methods for deformation analysis which have been quoted in Section (4) make use of interpolations of the original point clouds.

In addition to DSM data comparison in many periods monitoring, this paper also adopted the method to compare the part of choosing feature points.

\section{Validation experiments}

\section{Data Acquisition}

Through measurement we select an area including a ground fissure in four periods, the view data was carried out difference operation to generate DSM, Land subsidence rate was gained based on DSM comparison in this area, Figure 1 gives the part of test result about the region. Figure 2 shows the DSM model of this area. The result show that the subsidence is $2 \sim 10 \mathrm{~cm} / \mathrm{a}$ in the area . 


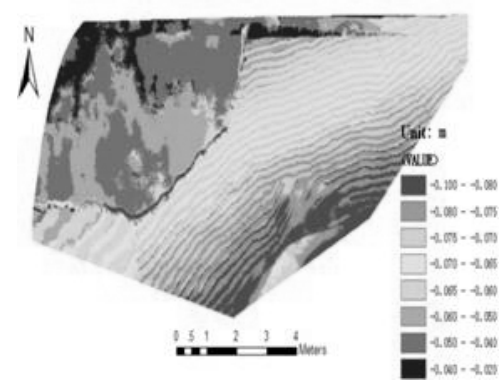

Fig.1 Differential DSM of the test area during Oct. 2009 to Oct. 2010

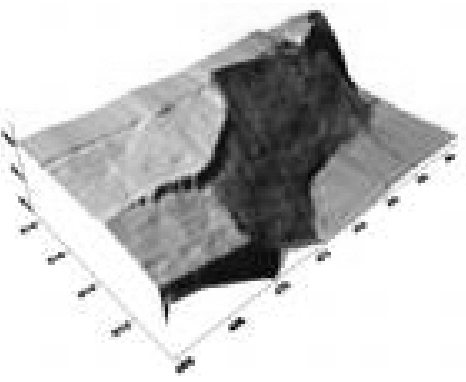

Fig.2 The picture of $3 \mathrm{D}$ rendering

Besides analysis ground subsidence by using the DSM comparison, furthermore, the partial features check-point was respectively chosen in two areas and carried out elevation difference to get $\Delta Z_{i}=Z^{t}-Z^{t+1}$, and then analysis ground subsidence based on equation (4)

$$
R M S=\sqrt{\frac{\sum\left(\Delta Z_{i}\right)^{2}}{n}}
$$

$R M S$ is Root Mean Square. Test results are shown in table 1.

Table 1. Results of subsidence monitoring based on control points $(\mathrm{cm})$

\begin{tabular}{ccccc}
\hline Monitoring period & $\begin{array}{c}\text { Numbers of Control } \\
\text { points }\end{array}$ & $\begin{array}{r}\text { Maximum } \\
\text { subsidence }\end{array}$ & $\begin{array}{c}\text { Minimum } \\
\text { subsidence }\end{array}$ & RMS \\
\hline Oct.2010-Oct.2009 & 21 & 12.1 & 1.5 & 8.1 \\
\hline Oct.2010-Apr.2010 & 20 & 10.2 & 1.2 & 5.5 \\
\hline Oct.2010-Jun.2010 & 16 & 5.3 & 0.7 & 3.5 \\
\hline
\end{tabular}

According to the measurement data collected from ground control points, average subsidence rate is $6 \sim 8 \mathrm{~cm} / \mathrm{a}$, the result nearly is in the same magnitude with DSM comparison results, this show that land subsidence monitoring method is accurate in this area.

\section{The results of ground fissure monitoring}

Most of ground fissure is caused by land subsidence in this test area. Through analysis of the 3D laser scanning data, we obtain the state surrounding ground fissure. Similarly to land subsidence analysis, we studied the ground fissure distribution and trend, test results shown in table 2.

Table 2. Results of subsidence monitoring based on control points $(\mathrm{cm})$

\begin{tabular}{cccccc}
\hline \multirow{2}{*}{ Monitoring period } & Check points position & $\begin{array}{c}\text { Number of } \\
\text { check points }\end{array}$ & $R M S_{\Delta X}$ & $R M S_{\Delta X}$ & $R M S_{\Delta Z}$ \\
\hline \multirow{2}{*}{ Oct.2010- Oct.2009 } & North direction & 10 & 0.9 & 1.5 & 6.7 \\
\cline { 2 - 6 } & South direction & 10 & 0.7 & 1.3 & 9.8 \\
\hline \multirow{2}{*}{ Oct.2010- Apr.2010 } & North direction & 12 & 0.5 & 1.1 & 4.7 \\
\cline { 2 - 6 } & South direction & 12 & 0.3 & 0.8 & 7.3 \\
\hline \multirow{2}{*}{ Oct.2010-Jun.2010 } & North direction & 9 & 0.4 & 0.9 & 2.8 \\
\cline { 2 - 6 } & South direction & 9 & 0.2 & 0.5 & 4.8 \\
\hline
\end{tabular}




\section{Comparison of results of land subsidence}

For the purpose to test ability that TLS monitoring land subsidence and ground fissure, and better research land subsidence and ground fissures change feature in the Xi' an southern suburb, some control points was selected, which have the same position with leveling measurement stations, The subsidence rate, shift rate was compared with leveling measurement in chosen stations, the compared results is listed in table 3.

$\Delta \mathrm{H}$ in the table 3 is calculated according to the formula (5).

$$
\Delta H=H_{\text {leveling }}-H_{T L S} \text {. }
$$

Table 3. Comparison of subsidence results $(\mathrm{cm})$

\begin{tabular}{ccc}
\hline Point & $\Delta \mathrm{H}($ Oct.2009-Apr.2010) & $\Delta \mathrm{H}($ Oct.2009-Oct.2010) \\
\hline A1 & -0.11 & 0.13 \\
\hline A2 & 0.15 & 0.10 \\
\hline A3 & 0.19 & 0.17 \\
\hline A4 & 0.21 & -0.24
\end{tabular}

It can be seen in the table that the mutual deviation between TLS scanning and leveling survey is less than $0.3 \mathrm{~cm}$, and has good consistency in the whole monitored stations. TLS technology fully can be used in land subsidence and ground fissure monitoring in the city.

\section{Conclusions}

From this paper test data, it can be seen that the land subsidence and ground fissure of stretch have the same direction in $\mathrm{Xi}$ ' an, in addition where there is large amount of land subsidence, the ground fissure development and activities are very fierce. There is direct relationship between land subsidence and ground fissures spatio-temporal distribution and its direction.

Further problems might arise when computing the difference ( $\triangle \mathrm{DSM})$ between DSMs come from surfaces captured in the different periods, e.g. due to registration errors or to lack of data. Future work will study how to generate better DSM in the local area of ground fissure. Further improvements are required on the integration of results come from adjacent regions.

\section{Acknowledgement}

This work was supported by National Natural Scientific Foundation of China (NSFC) grants (No. 41372330).

\section{References}

[1] Leake, S.A., 1997. http://geochange.er.usgs.gov/sw/changes/anthropogenic/subside/ of subordinate document. Cited: 6 Jan 2004.

[2] Bitelli,G.,F.Bonsignore, and M. Unguendoli,2000. Leveling and GPS networks to monitor ground subsidence in the Southern Po Valley. Journal of Geodynamics, Volume 30, Issue 3:355-369.

[3] Ferretti, A.,C. Prati, and F.Rocca,2000.Nonlinear subsidence rate estimation using permanent 
scatterers in differential SAR interferometry. IEEE Transactions on Geoscience and Remote Sensing, Vol. 38: 2202-2212.

[4] Ferretti, A., C. Prati, and F. Rocca,2001. Permanent scatterers in SAR interferometry. IEEE Transactions on Geoscience and Remote Sensing, Vol. 39: 8-20.

[5] Schroedel, J., 2002. Engineering and Design: Structural Deformation Surveying (EM 1110-2-1009), US Army Corps of Engineers, 2002, Washington, DC.

[6] Lee J., Snyder P.K., Fisher P.F., 1992. Modeling the effect of data errors on feature extraction from digital elevation models, Photogrammetric Engineering and Remote Sensing, 58(10): 1461-1467.

[7] Hajela, D., 1990. Obtaining centimeter-precision heights by GPS over small areas, GPS World, $1(1)$.

[8] Graham, L.C, 1974. Synthetic interferometer radar for topographic mapping. Proceedings of the IEEE, 62: 763-768.

[9] Massonnet, D. And K. L. Feigl, 1998. Radar interferometry and its application to changes in the Earth's surface, Rev. Geophys. 36: 441 500. 